\title{
Correction to: Post-translational modifications of Beclin 1 provide multiple strategies for autophagy regulation
}

\author{
Sandra M. Hill ${ }^{1} \cdot$ Lidia Wrobel $^{1} \cdot$ David C. Rubinsztein $^{1,2}$
}

Published online: 9 May 2019

๑ ADMC Associazione Differenziamento e Morte Cellulare 2019

\section{Correction to: Cell Death Differentiation}

https://doi.org/10.1038/s41418-018-0254-9

published online 13 December 2018

Reference 45 was incorrect in the original version of this article. The correct reference is:

45. Fernández ÁF, Sebti S, Wei Y, Zou Z, Shi M, McMillan KL, et al. Disruption of the beclin 1-BCL2 autophagy regulatory complex promotes longevity in mice. Nature. 2018;558:136-40.

The reference has been updated in the online html and PDF.

David C. Rubinsztein

dcr1000@cam.ac.uk

1 Department of Medical Genetics, Cambridge Institute for Medical Research, Wellcome Trust/MRC Building, Cambridge Biomedical Campus, Hills Road, Cambridge CB2 0XY, UK

2 UK Dementia Research Institute, University of Cambridge,

Cambridge Institute for Medical Research, Wellcome Trust/MRC Building, Cambridge Biomedical Campus, Hills Road,

Cambridge CB2 OXY, UK 